\title{
Research on Safety Level Evaluation of Island-type Petrochemical Park Based on ANP
}

\author{
Qianyu Guo ${ }^{1}$, Jian Guo ${ }^{2, *}$, Bingyuan Hong ${ }^{2, *}$ \\ ${ }^{1}$ School of Ships and Maritime, Zhejiang Ocean University, Zhoushan, 316022, China \\ ${ }^{2}$ School of Petrochemical and Environment, Zhejiang Ocean University, Zhoushan, 316022, China
}

\begin{abstract}
The inherent dangers of the petrochemical industry and the extreme meteorological conditions in the coastal areas make the island-type petrochemical parks have complicated safety hazards. In order to improve the safety management capability of my country's island-type petrochemical parks, this paper analyzes the risk sources of the island-type petrochemical parks from the four subsystems of human, machine, environment and management, and uses the network analytic hierarchy process (ANP) to calculate the correlation weights between the indicators. The establishment of an evaluation model for the safety level of island-type petrochemical parks and quantitative analysis of the safety level of island-type petrochemical parks are of great significance for guiding the safety work of my country's island-type petrochemical parks.
\end{abstract}

\section{Preface}

The petrochemical industry is developing rapidly in China. However, due to the inherent dangers of the raw materials and products of petrochemical companies, the development of the petrochemical industry in China is facing increasingly severe social and environmental pressures. In recent years, China has begun to refer to places such as Singapore's Jurong Island. Relying on the rich rock-based islands in the offshore China to build an island-type petrochemical park.

This kind of petrochemical park can avoid densely populated areas and effectively dilute pollutants. However, extreme weather phenomena such as frequent typhoons in the ocean and salt spray corrosion and other destructive factors have brought very negative effects on petrochemical enterprises and equipment. At present, domestic and foreign researches on the hazards of petrochemical parks mainly include: K. Yang et al. [1] used a safety risk assessment method that combines safety checklists with analytic hierarchy and accident analysis to establish a safety hierarchy. Q. Xia et al. [2] established a mathematical model for the safety risk calculation of large petrochemical port areas based on the analytic hierarchy process. L. Tong et al. [3] analyzed the causes of high environmental risks in the petrochemical industry and countermeasures. S.P. Cui et al. [4] used social security risk assessment methods to explore the technical measures of UAV countermeasures and prevention and control of petrochemical enterprises. S. Mi et al. [5] carried out risk identification and accident consequence prediction and analysis of petrochemical projects. On the basis of analyzing the environmental risk characteristics of petrochemical companies, Q. Jia et al. [6] constructed a comprehensive evaluation index system for sudden environmental risks in petrochemical companies, and established a corresponding risk evaluation model. According to the influencing factors involved in the characterization of hazardous chemical process, Q. Cheng et al. [7] divided the risk level of hazardous chemical process into two parts: inherent process risk and safety compensation. C.Q. Zhang [8] discussed the problems and deviations in the HSE risk analysis method and application of petrochemical construction enterprises, and put forward rectification suggestions based on the actual HSE management of petrochemical construction enterprises. Y. Li [9] took the planning environment evaluation of a petrochemical park as an example, and put forward the environmental impact index system suitable for the petrochemical park and the issues that should be focused on in the planning environmental evaluation.

Although Chinese scholars have conducted a lot of related research, in China, there are still few island-type petrochemical parks, and there is a lack of systematic research on the safety of island-type petrochemical parks. Therefore, the methods and means of system engineering are used to carry out the risk of this kind of petrochemical park. Analysis is necessary.

\section{Construction of safety level indicator system for island-type petrochemical parks}

The safety level index of the island-type petrochemical park refers to the factors that can reflect the safety level of the island-type petrochemical park, which has an important impact on the safety status of the island-type petrochemical park. The theory of the four elements of the accident system believes that the influencing factors 
leading to accidents only need to be concentrated in the four aspects of human, machine, environment and management. Human factors are the most active and the most difficult to control. Secondly, equipment and technical factors are also very critical links in safe production in the petrochemical industry. Since there are relatively few practices in the island-type petrochemical park at home and abroad, the relevant production equipment and technology are based on the terrestrial environment. However, the island-type petrochemical park is located in the ocean, and harsh environments such as strong corrosion and salt spray will accelerate the corrosion of the equipment, thereby shortening the service life and reliability of the equipment. Therefore, technical factors are also an important basis for the stable operation of the island-type petrochemical park. Environmental factors are also very important for the stable operation of the island-type petrochemical park, mainly due to meteorological and environmental factors such as typhoons, rainstorms and salt fog. Management factors include the macro safety standard system, safety supervision system and park safety supervision. As an important infiltration factor, it has a great impact on personnel, technology and equipment.

This paper analyzes and categorizes relevant factors by collating and analyzing the safety-related documents of the island-type petrochemical park, thereby establishing an index system for the safety level of the island-type petrochemical park. This paper takes the safety management of the island-type petrochemical park as the target layer, the safety level of the island-type petrochemical park as the solution layer, and the safety level of personnel subsystems, equipment and technology subsystems, environmental subsystems, and management subsystems as the security level. The first-level indicator layer is divided into 14 second-level indicators. The safety level indicator system of the island-type petrochemical park is shown in Figure 1.

\section{Determination of indicator weight}

Analytic Network Process is a decision-making method suitable for complex structures proposed by Professor T.L.Saaty in the 1990s. It is a decision-making method developed gradually on the basis of analytic hierarchy process[10]. The traditional analytic hierarchy process (AHP) constructs a hierarchical structure, but does not consider the interrelationship between the indicators, while ANP considers the interdependence between the indicators on the basis of the analytic hierarchy process to determine the index weight More scientific and accurate. Network hierarchy analysis usually takes the following steps: constructing network hierarchy, constructing super matrix, constructing weighted super matrix, and calculating limit super matrix.

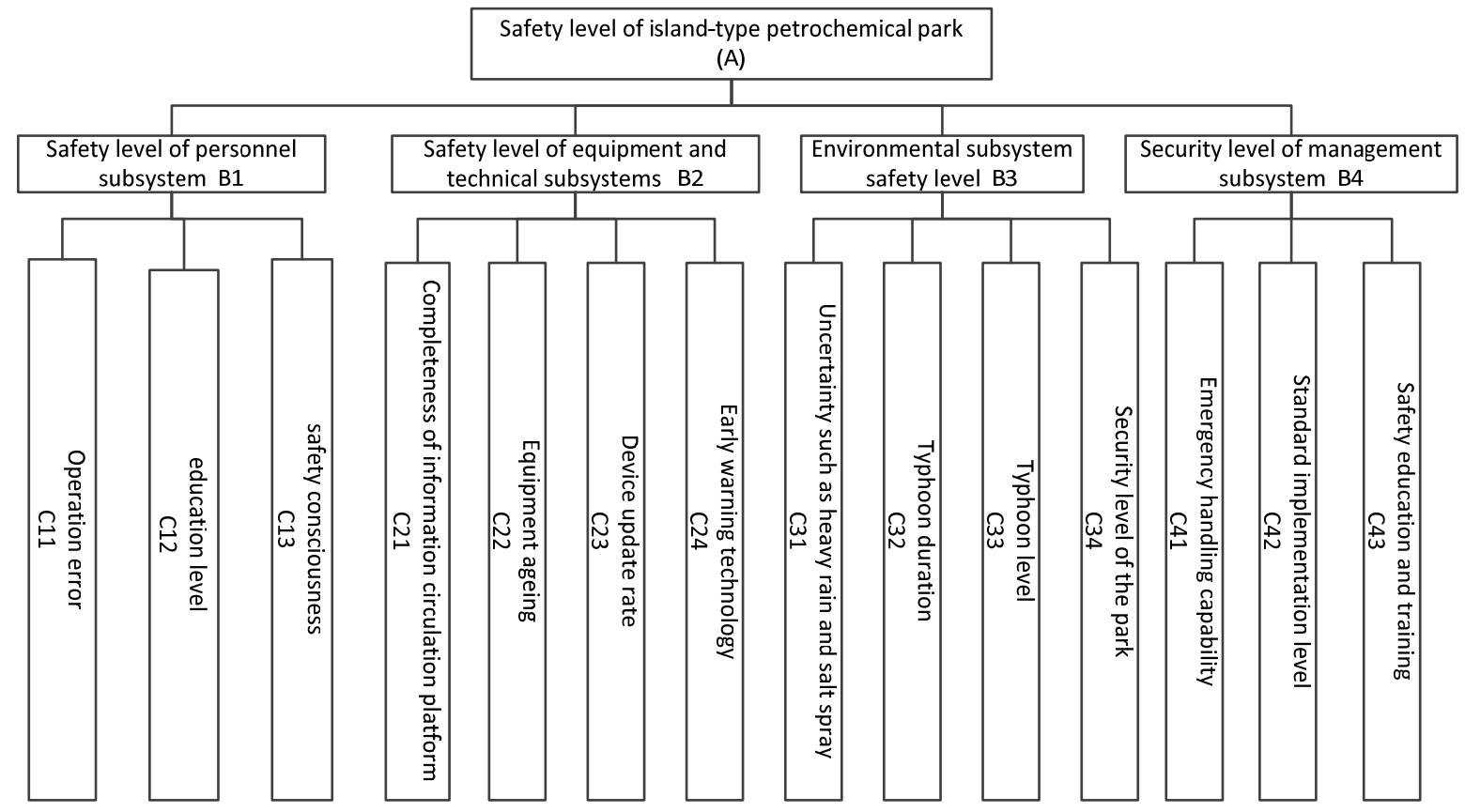

Fig. 1. Safety level indicator system for island-type petrochemical parks

\subsection{ANP model construction}

The ANP model constructed in this paper is composed of a control layer and 4 network layers. The control layer is the security level of the island-type petrochemical park, and the network layer is the security level of the personnel subsystem, the security level of the equipment and technology subsystem, the security level of the environmental subsystem, and the security level of the management subsystem. The constructed ANP model is shown in Figure 2. 


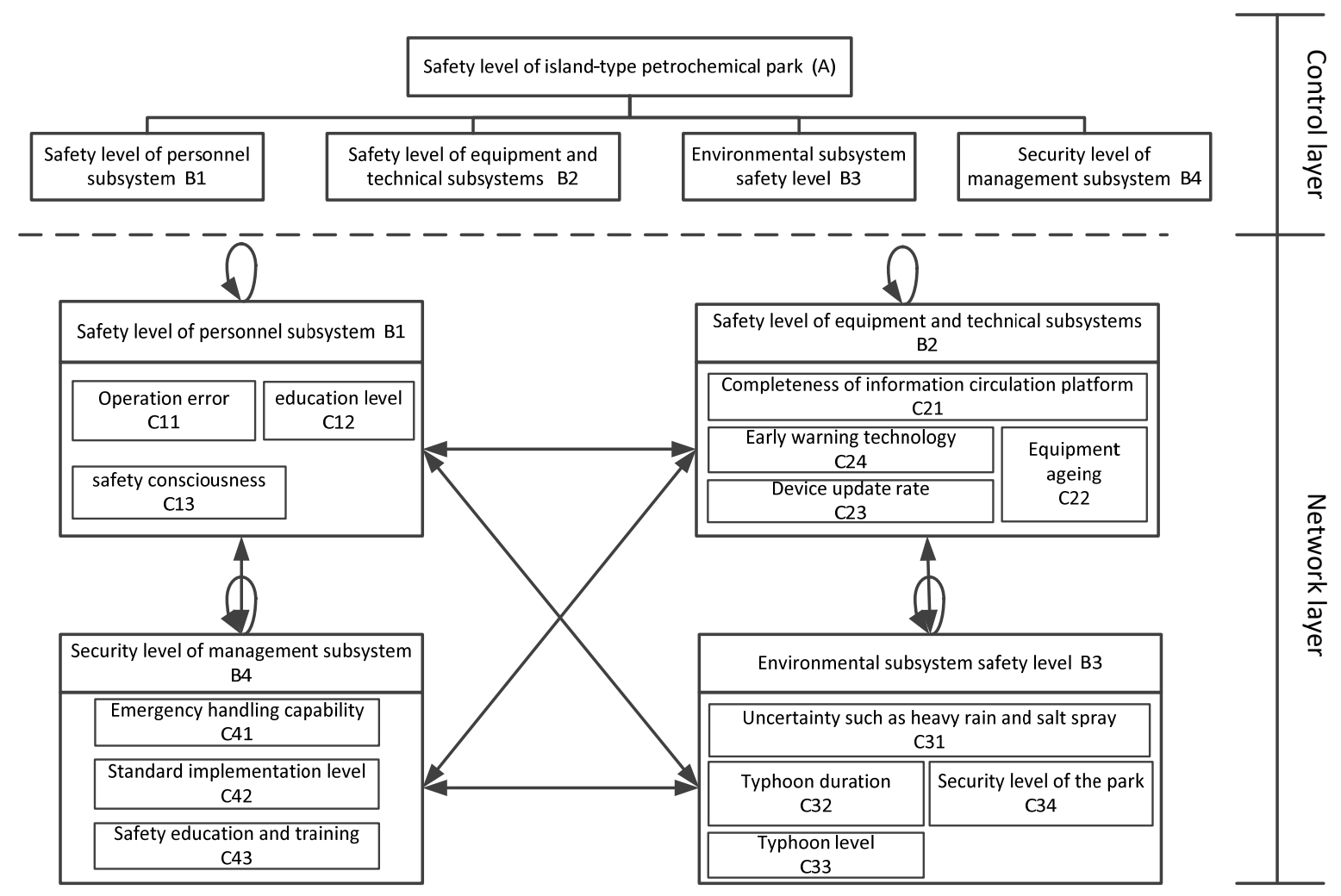

Fig. 2. ANP model of safety level of island-type petrochemical park.

\subsection{Constructing weightless super matrix $W$}

The control layer elements in the ANP structure are the first-level indicators, and the network layer is the secondlevel indicators. In the safety level indicator system of island-type petrochemical parks, the first-level indicators are used as criteria to determine the mutual influence between the second-level indicators. Since the elements in the ANP structure are interdependent, the dominated elements under each decision criterion will be compared with the 1-9 scale method, and a judgment matrix will be constructed and formed on this basis, which will pass the characteristics of the consistency test The vector is expressed as a matrix, and the feature vectors of all elements are summarized into a weightless super matrix, as shown in Table 1.

Tab. 1. Weightless super matrix $W$.

\begin{tabular}{|c|c|c|c|c|c|c|c|c|c|c|c|c|c|c|}
\hline & $\mathrm{C} 11$ & $\mathrm{C} 12$ & $\mathrm{C} 13$ & $\mathrm{C} 21$ & $\mathrm{C} 22$ & $\mathrm{C} 23$ & $\mathrm{C} 24$ & $\mathrm{C} 31$ & $\mathrm{C} 32$ & $\mathrm{C} 33$ & $\mathrm{C} 34$ & $\mathrm{C} 41$ & $\mathrm{C} 42$ & $\mathrm{C} 43$ \\
\hline $\mathrm{C} 11$ & 0.0000 & 0.1000 & 0.7500 & 0.2098 & 0.0000 & 0.5499 & 0.5499 & 0.5499 & 0.5499 & 0.5499 & 0.5499 & 0.0000 & 0.5499 & 0.5499 \\
\hline $\mathrm{C} 12$ & 0.5000 & 0.0000 & 0.2500 & 0.2402 & 0.0000 & 0.2098 & 0.2098 & 0.2098 & 0.2098 & 0.2098 & 0.2098 & 0.0000 & 0.2098 & 0.2098 \\
\hline $\mathrm{C} 13$ & 0.5000 & 0.9000 & 0.0000 & 0.5499 & 0.0000 & 0.2402 & 0.2402 & 0.2402 & 0.2402 & 0.2402 & 0.2402 & 0.0000 & 0.2402 & 0.2402 \\
\hline $\mathrm{C} 21$ & 0.2649 & 0.2649 & 0.2649 & 0.0000 & 0.3108 & 0.2857 & 0.4934 & 0.2649 & 0.2544 & 0.2649 & 0.2649 & 0.2649 & 0.2649 & 0.2649 \\
\hline $\mathrm{C} 22$ & 0.0990 & 0.0990 & 0.0990 & 0.1220 & 0.0000 & 0.1429 & 0.1958 & 0.0990 & 0.0975 & 0.0990 & 0.0990 & 0.0990 & 0.0990 & 0.0990 \\
\hline $\mathrm{C} 23$ & 0.2066 & 0.2066 & 0.2066 & 0.3196 & 0.1958 & 0.0000 & 0.3108 & 0.2066 & 0.1839 & 0.2066 & 0.2066 & 0.2066 & 0.2066 & 0.2066 \\
\hline $\mathrm{C} 24$ & 0.4295 & 0.4295 & 0.4295 & 0.5584 & 0.4934 & 0.5714 & 0.0000 & 0.4295 & 0.4642 & 0.4295 & 0.4295 & 0.4295 & 0.4295 & 0.4295 \\
\hline C31 & 0.1970 & 0.1970 & 0.2185 & 0.2185 & 0.0000 & 0.1970 & 0.1970 & 0.0000 & 0.2000 & 0.4434 & 0.1634 & 0.1970 & 0.1970 & 0.1970 \\
\hline $\mathrm{C} 32$ & 0.4176 & 0.4176 & 0.3835 & 0.3835 & 0.0000 & 0.4176 & 0.4176 & 0.4934 & 0.0000 & 0.3874 & 0.5396 & 0.4176 & 0.4176 & 0.4176 \\
\hline C33 & 0.2611 & 0.2611 & 0.2732 & 0.2732 & 0.0000 & 0.2611 & 0.2611 & 0.3108 & 0.4000 & 0.0000 & 0.2970 & 0.2611 & 0.2611 & 0.2611 \\
\hline C34 & 0.1242 & 0.1242 & 0.1248 & 0.1248 & 0.0000 & 0.1242 & 0.1242 & 0.1958 & 0.4000 & 0.1692 & 0.0000 & 0.1242 & 0.1242 & 0.1242 \\
\hline $\mathrm{C} 41$ & 0.3275 & 0.3275 & 0.3275 & 0.3275 & 0.3275 & 0.3275 & 0.3275 & 0.3275 & 0.3275 & 0.3275 & 0.3275 & 0.0000 & 0.5000 & 0.5000 \\
\hline $\mathrm{C} 42$ & 0.4126 & 0.4126 & 0.4126 & 0.4126 & 0.4126 & 0.4126 & 0.4126 & 0.4126 & 0.4126 & 0.4126 & 0.4126 & 0.6667 & 0.0000 & 0.5000 \\
\hline $\mathrm{C} 43$ & 0.2599 & 0.2599 & 0.2599 & 0.2599 & 0.2599 & 0.2599 & 0.2599 & 0.2599 & 0.2599 & 0.2599 & 0.2599 & 0.3333 & 0.5000 & 0.0000 \\
\hline
\end{tabular}


Tab. 2. Weight super matrix $\bar{W}$.

\begin{tabular}{c|c|c|c|c|c|c|c|c|c|c|c|c|c|c}
\hline & $\mathrm{C} 11$ & $\mathrm{C} 12$ & $\mathrm{C} 13$ & $\mathrm{C} 21$ & $\mathrm{C} 22$ & $\mathrm{C} 23$ & $\mathrm{C} 24$ & $\mathrm{C} 31$ & $\mathrm{C} 32$ & $\mathrm{C} 33$ & $\mathrm{C} 34$ & $\mathrm{C} 41$ & $\mathrm{C} 42$ & $\mathrm{C} 43$ \\
\hline C11 & 0.0000 & 0.0168 & 0.1259 & 0.0352 & 0.0000 & 0.0923 & 0.0923 & 0.0923 & 0.0923 & 0.0923 & 0.0923 & 0.0000 & 0.0923 & 0.0923 \\
\hline C12 & 0.0840 & 0.0000 & 0.0420 & 0.0403 & 0.0000 & 0.0352 & 0.0352 & 0.0352 & 0.0352 & 0.0352 & 0.0352 & 0.0000 & 0.0352 & 0.0352 \\
\hline C13 & 0.0840 & 0.1511 & 0.0000 & 0.0923 & 0.0000 & 0.0403 & 0.0403 & 0.0403 & 0.0403 & 0.0403 & 0.0403 & 0.0000 & 0.0403 & 0.0403 \\
\hline C21 & 0.1300 & 0.1300 & 0.1300 & 0.0000 & 0.1525 & 0.1402 & 0.2421 & 0.1300 & 0.1248 & 0.1300 & 0.1300 & 0.1300 & 0.1300 & 0.1300 \\
\hline C22 & 0.0486 & 0.0486 & 0.0486 & 0.0598 & 0.0000 & 0.0701 & 0.0961 & 0.0486 & 0.0478 & 0.0486 & 0.0486 & 0.0486 & 0.0486 & 0.0486 \\
\hline C23 & 0.1014 & 0.1014 & 0.1014 & 0.1568 & 0.0961 & 0.0000 & 0.1525 & 0.1014 & 0.0902 & 0.1014 & 0.1014 & 0.1014 & 0.1014 & 0.1014 \\
\hline C24 & 0.2107 & 0.2107 & 0.2107 & 0.2740 & 0.2421 & 0.2804 & 0.0000 & 0.2107 & 0.2278 & 0.2107 & 0.2107 & 0.2107 & 0.2107 & 0.2107 \\
\hline C31 & 0.0112 & 0.0112 & 0.0124 & 0.0124 & 0.0000 & 0.0112 & 0.0112 & 0.0000 & 0.0113 & 0.0251 & 0.0093 & 0.0112 & 0.0112 & 0.0112 \\
\hline C32 & 0.0237 & 0.0237 & 0.0217 & 0.0217 & 0.0000 & 0.0237 & 0.0237 & 0.0280 & 0.0000 & 0.0220 & 0.0306 & 0.0237 & 0.0237 & 0.0237 \\
\hline C33 & 0.0148 & 0.0148 & 0.0155 & 0.0155 & 0.0000 & 0.0148 & 0.0148 & 0.0176 & 0.0227 & 0.0000 & 0.0168 & 0.0148 & 0.0148 & 0.0148 \\
\hline C34 & 0.0070 & 0.0070 & 0.0071 & 0.0071 & 0.0000 & 0.0070 & 0.0070 & 0.0111 & 0.0227 & 0.0096 & 0.0000 & 0.0070 & 0.0070 & 0.0070 \\
\hline C41 & 0.0933 & 0.0933 & 0.0933 & 0.0933 & 0.0933 & 0.0933 & 0.0933 & 0.0933 & 0.0933 & 0.0933 & 0.0933 & 0.0000 & 0.1424 & 0.1424 \\
\hline C42 & 0.1175 & 0.1175 & 0.1175 & 0.1175 & 0.1175 & 0.1175 & 0.1175 & 0.1175 & 0.1175 & 0.1175 & 0.1175 & 0.1898 & 0.0000 & 0.1424 \\
\hline C43 & 0.0740 & 0.0740 & 0.0740 & 0.0740 & 0.0740 & 0.0740 & 0.0740 & 0.0740 & 0.0740 & 0.0740 & 0.0740 & 0.0949 & 0.1424 & 0.0000 \\
\hline
\end{tabular}

Tab. 3. Super limit matrix $W^{\infty}$.

\begin{tabular}{c|c|c|c|c|c|c|c|c|c|c|c|c|c|c}
\hline & $\mathrm{C} 11$ & $\mathrm{C} 12$ & $\mathrm{C} 13$ & $\mathrm{C} 21$ & $\mathrm{C} 22$ & $\mathrm{C} 23$ & $\mathrm{C} 24$ & $\mathrm{C} 31$ & $\mathrm{C} 32$ & $\mathrm{C} 33$ & $\mathrm{C} 34$ & $\mathrm{C} 41$ & $\mathrm{C} 42$ & $\mathrm{C} 43$ \\
\hline C11 & 0.0631 & 0.0631 & 0.0631 & 0.0631 & 0.0631 & 0.0631 & 0.0631 & 0.0631 & 0.0631 & 0.0631 & 0.0631 & 0.0631 & 0.0631 & 0.0631 \\
\hline $\mathrm{C} 12$ & 0.0327 & 0.0327 & 0.0327 & 0.0327 & 0.0327 & 0.0327 & 0.0327 & 0.0327 & 0.0327 & 0.0327 & 0.0327 & 0.0327 & 0.0327 & 0.0327 \\
\hline $\mathrm{C} 13$ & 0.0459 & 0.0459 & 0.0459 & 0.0459 & 0.0459 & 0.0459 & 0.0459 & 0.0459 & 0.0459 & 0.0459 & 0.0459 & 0.0459 & 0.0459 & 0.0459 \\
\hline $\mathrm{C} 21$ & 0.1412 & 0.1412 & 0.1412 & 0.1412 & 0.1412 & 0.1412 & 0.1412 & 0.1412 & 0.1412 & 0.1412 & 0.1412 & 0.1412 & 0.1412 & 0.1412 \\
\hline $\mathrm{C} 22$ & 0.0599 & 0.0599 & 0.0599 & 0.0599 & 0.0599 & 0.0599 & 0.0599 & 0.0599 & 0.0599 & 0.0599 & 0.0599 & 0.0599 & 0.0599 & 0.0599 \\
\hline C23 & 0.1110 & 0.1110 & 0.1110 & 0.1110 & 0.1110 & 0.1110 & 0.1110 & 0.1110 & 0.1110 & 0.1110 & 0.1110 & 0.1110 & 0.1110 & 0.1110 \\
\hline C24 & 0.1965 & 0.1965 & 0.1965 & 0.1965 & 0.1965 & 0.1965 & 0.1965 & 0.1965 & 0.1965 & 0.1965 & 0.1965 & 0.1965 & 0.1965 & 0.1965 \\
\hline C31 & 0.0110 & 0.0110 & 0.0110 & 0.0110 & 0.0110 & 0.0110 & 0.0110 & 0.0110 & 0.0110 & 0.0110 & 0.0110 & 0.0110 & 0.0110 & 0.0110 \\
\hline C32 & 0.0219 & 0.0219 & 0.0219 & 0.0219 & 0.0219 & 0.0219 & 0.0219 & 0.0219 & 0.0219 & 0.0219 & 0.0219 & 0.0219 & 0.0219 & 0.0219 \\
\hline C33 & 0.0143 & 0.0143 & 0.0143 & 0.0143 & 0.0143 & 0.0143 & 0.0143 & 0.0143 & 0.0143 & 0.0143 & 0.0143 & 0.0143 & 0.0143 & 0.0143 \\
\hline C34 & 0.0071 & 0.0071 & 0.0071 & 0.0071 & 0.0071 & 0.0071 & 0.0071 & 0.0071 & 0.0071 & 0.0071 & 0.0071 & 0.0071 & 0.0071 & 0.0071 \\
\hline C41 & 0.0957 & 0.0957 & 0.0957 & 0.0957 & 0.0957 & 0.0957 & 0.0957 & 0.0957 & 0.0957 & 0.0957 & 0.0957 & 0.0957 & 0.0957 & 0.0957 \\
\hline C42 & 0.1183 & 0.1183 & 0.1183 & 0.1183 & 0.1183 & 0.1183 & 0.1183 & 0.1183 & 0.1183 & 0.1183 & 0.1183 & 0.1183 & 0.1183 & 0.1183 \\
\hline C43 & 0.0812 & 0.0812 & 0.0812 & 0.0812 & 0.0812 & 0.0812 & 0.0812 & 0.0812 & 0.0812 & 0.0812 & 0.0812 & 0.0812 & 0.0812 & 0.0812 \\
\hline
\end{tabular}




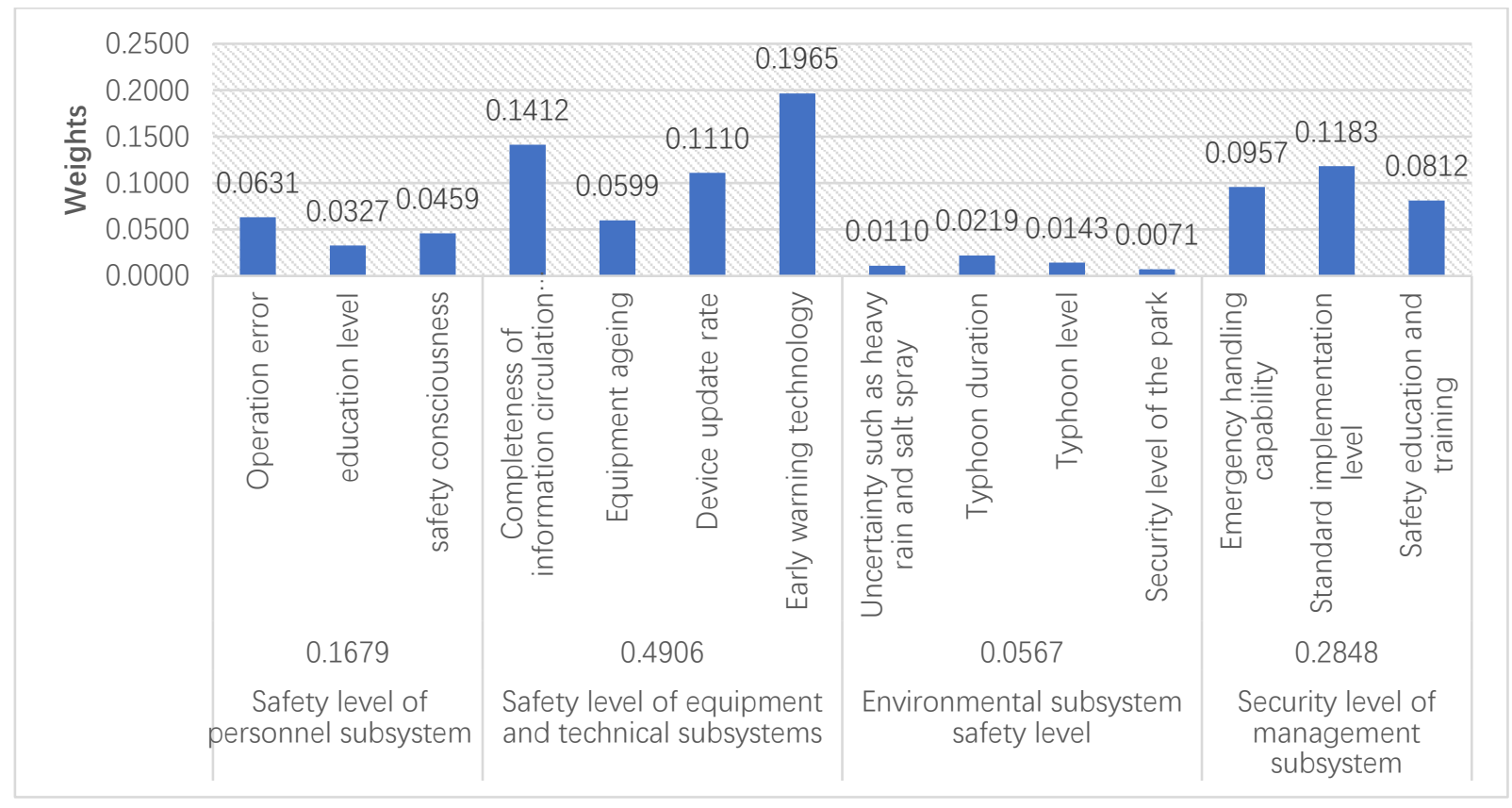

Fig. 3. The weight of each index.

\subsection{Solve the weight super matrix $\bar{W}$ and super limit matrix $W^{\infty}$}

On the basis of the weightless super matrix $W$, the super matrix is normalized and multiplied by the weighting factor to obtain the weighting matrix $\bar{W}$. The weighted super matrix $\bar{W}$ is shown in Table 2. Stabilize the super matrix to generate the limit matrix $W^{\infty}$. The limit matrix $W^{\infty}$ is shown in Table 3. Due to the complex calculation process, such professional software as Super Decision or YAANP can be used to complete.

\subsection{Analysis of weighting results}

The final weight value of each index is shown in Figure 3. According to the results in Figure 3, among the four firstlevel evaluation indicators, the weight of the safety level of equipment and technical subsystems is as high as 0.4906 , which highlights the importance of ensuring the smooth operation of equipment and improving early warning technology in the island-type petrochemical park in its special environment. Sex. The safety level of the management subsystem, the safety level of the personnel subsystem, and the safety level of the environmental subsystem ranked second, third, and fourth. In the management subsystem, the standard implementation degree index has the highest weight, which is 0.1183 , indicating that the island-type petrochemical park must strictly implement the production standards under complex production conditions to ensure safe production. In the personnel subsystem, the weight of the operation error index is the highest, which is 0.0631 , which also shows that the standard must be strictly implemented under complex production conditions to reduce the operation error rate. The weight of the typhoon grade index in the environmental subsystem reached 0.0219, indicating that special attention should be paid to typhoon warning and prevention and control measures in the island-type petrochemical park.

\section{Conclusion}

1) This paper applies the Analytic Network Process (ANP) to the safety evaluation of island-type petrochemical parks, and establishes a safety evaluation consisting of 4 firstlevel indicators and 14 second-level indicators from the aspects of personnel, technology and equipment, environment and management. System and calculation model, put forward the overall safety classification standard.

2) Aiming at the island-type petrochemical park, this paper adopts the ANP method for safety assessment, assists the petrochemical park in safety early warning, and realizes the quantitative analysis of the qualitative problem of the safety level evaluation of the petrochemical park.

3) In the island environment, there are special circumstances such as complex and changeable natural environment, insufficient rescue capability, and inconvenient transportation [13]. The design of safety indicators for island-type petrochemical parks has a lot of content, and the choice of indicators has a greater impact on the reliability of the final evaluation results. In practice, indicators should be selected scientifically and reasonably based on actual conditions.

\section{Acknowledgments}

Industrial Project of Public Technology Research of Zhejiang Province Science and Technology Department (LGG18E040001), and Scientific Research Project of Zhejiang Province Education Department (Y20173854). 


\section{References}

1. K. Yang, Y. Wang, Y. Wang, X.M. Zhou, L.X. Gu. Application of Analytic Hierarchy Process in Safety Risk Assessment of Petrochemical Enterprises. Shanghai Environmental Science. J. (06): 36-37+39, (1994)

2. Q. Xia, R.T. Shen. Safety risk assessment index system and assessment methods for large petrochemical port areas. Water Transport Engineering. J.(10):95-98, (2020)

3. L. Tong, L. Cao, J.W. Li, H. Jiang, L.J. Ran. Analysis of the causes of high environmental risks in the petrochemical industry and countermeasures. Environmental Science and Management. J.37(05):66-71, (2012)

4. S.P. Cui, C.G. Li. Analysis of UAV Safety Risk Prevention and Control in Petroleum and Petrochemical Enterprises. China Safety Production Science and Technology. J.15(S2):20-22, (2019)

5. S. Mi, X.W. Wang, B.D. Wang, H.G. Feng. Research on Environmental Risk Assessment of Petrochemical Enterprises. Environmental Science and Management. J.37(10):181-186. (2012)

6. Q. Jia, L. Huang, Z.W. Yuan, X.F. Zhang. Research on assessment and classification method of sudden environmental risk in petrochemical enterprises. Journal of Environmental Sciences. J.30(07): 15101517. (2010)

7. Q. Cheng, Y.Q. Guo, L.J. Zhang, G. Tao, X. Zeng. Research on the Risk Level Evaluation Index System of Hazardous Chemical Processes in Petrochemical Enterprises. China Work Safety Science and Technology. J.7(10):89-92, (2011)

8. C.Q. Zhang. HSE risk analysis and application of petrochemical construction enterprises. Chinese and foreign entrepreneurs. J. (06): 8-10, (2014)

9. Y. Li. Preliminary study on the index system and key points of the environmental impact assessment of petrochemical park planning: A case of a petrochemical industrial zone in Guangdong Province. Environmental Science and Management. J.35(09):183-186, (2010)

10. M.Y. Sun. Comparison of Analytic Hierarchy Process (AHP) and Analytic Network Process (ANP). Chinese and Foreign Entrepreneurs. J. (10): 67-68, (2014)

11. C.C. He, Y.M. Wang. A review of the network analytic hierarchy process. Research on Science and Technology Management. J.34(03):204-208+213, (2014)

12. Y.C. Guo, B. Wang, M. Yu. Research on extension evaluation of construction site safety management based on ANP. Safety. J.41(10):57-63, (2020)

13. X.Y. Huang, J.H. Ye. Analysis of fuzzy comprehensive evaluation of blasting safety of islandtype petrochemical projects based on AHP method. Rural Economy and Science. J.29(05):297-299, (2018)
14. Q. Xia, R.T. Shen. Safety risk assessment index system and assessment methods for large petrochemical port areas. Water Transport Engineering. J. (10): 95-98, (2020) 